SISTEMA
ELETRÔNICO
DE REVISTAS
SER I UfPR

\title{
Desenvolvimento urbano e saúde pública: impactos da construção da UHE de Belo Monte
}

\section{Urban development and public health: impacts of the construction of the Belo Monte HPP}

\author{
Douglas Pereira de SOUZA ${ }^{1 *}$, Wanhinna Regina Soares da SILVA², Gilberto Carlos CERVINSKI ${ }^{1}$, Bruno Dias
} dos SANTOS $^{1}$, Francisco de Assis COMARÚ ${ }^{1}$, Federico Bernardino Morante TRIGOSO ${ }^{1}$

${ }^{1}$ Universidade Federal do ABC (UFABC), Santo André, SP, Brasil.

${ }^{2}$ Instituto Federal do Pará (IFPA), Parauapebas, PA, Brasil.

*E-mail de contato: douglasdc7@hotmail.com

Artigo recebido em 25 de outubro de 2017, versão final aceita em 7 de julho de 2018.

RESUMO: $\quad$ O Brasil dispõe do maior potencial hídrico do mundo e suas principais bacias hidrográficas se encontram na região amazônica. Por isso, grandes projetos hidrelétricos estão sendo planejados e construídos no Norte do país. Entretanto, na fase de implantação de uma usina, trabalhadores são atraídos para o local da obra em busca de emprego, o que modifica a dinâmica populacional das áreas de influência do empreendimento. Nesse contexto, este artigo busca discutir os impactos no crescimento urbano da cidade de Altamira (PA) com a construção da UHE de Belo Monte, visando compreender sua interferência na saúde pública. Do ponto de vista da abordagem metodológica, foram utilizadas neste artigo a revisão bibliográfica e a pesquisa documental. Verificou-se que no início das obras em Altamira ocorreram modificações estruturais, do ponto de vista social, econômico e ambiental. As mudanças são percebidas pelo aumento populacional, que eleva a demanda nos serviços públicos, e pelo subdimensionamento dos dados censitários, que impacta diretamente a saúde pública, pois a elaboração de políticas públicas de atenção e financiamento do Sistema Único de Saúde (SUS) é regida pelo censo demográfico. Apesar de o município apresentar um aumento de 72,2\% da cobertura da atenção básica em 2017, somente com a realização de um novo censo será possível traçar um diagnóstico mais preciso sobre todas as transformações ocorridas no território de Altamira, principalmente as referentes à saúde pública.

Palavras-chaves: conflitos socioambientais; grandes empreendimentos; avaliação de impactos na saúde; Hidrelétrica de Belo Monte; Altamira (PA).

ABSTRACT: Brazil has the greatest water potential in the world and the main hydrographic basins are located in the Amazon region. Thus, large hydropower projects are being planned and built in the north region of the country. However, 
in the phase of power plant implantation, workers are attracted to the site in search of employment, which modifies the population dynamics of the area of influence of the enterprise. In this context, this article seeks to discuss the impacts on the urban growth of the city of Altamira (PA) in face of the construction of the Belo Monte hydroelectric power plant (HPP), in order to understand its interference in public health. Regarding the methodological approach, this article was based on bibliographic review and documentary research. It was verified that at the beginning of the construction in Altamira, there were structural changes in the social, economic, and environmental spheres. These changes are perceived through population increase, which raises the demand for public services; and through the underestimation of census data, which directly impacts public health, since the public health care policies and the Unified Health System (Sistema Único de Saúde - SUS) are governed by the Demographic Census. Although the municipality presented a $72.2 \%$ increase in Basic Care coverage in 2017, it will only be possible to draw a more precise diagnosis of all transformations occurring in Altamira, mainly those related to Public Health, after new census.

Keywords: social and environmental impacts; large enterprise; assessment of health impacts; Belo Monte hydroelectric power plant; Altamira (PA).

\section{Introdução}

No cenário mundial, segundo o relatório REN21 (2017), as usinas hidrelétricas representam a maior parte da energia renovável do mundo (cerca de $16,6 \%$ ) e apresentam grande potencial de expansão. Em comparação com outras alternativas para a geração de energia, as hidrelétricas mostram-se atraentes em termos de geração de energia e de custos. No Brasil, há condições favoráveis para o desenvolvimento e a consolidação da hidroeletricidade na engenharia nacional, principalmente porque o país dispõe do maior potencial hídrico do mundo, o que contribui para inserção dessa fonte renovável na matriz energética brasileira. Devido à escassez de grandes rios na região Centro-Sul do Brasil, a exploração de rios na região Norte ganhou importância estratégica para a expansão energética do país. Somente na Amazônia, o potencial para geração de energia hidrelétrica é estimado em 57,3 $\mathrm{GW}$, em virtude da riqueza hídrica encontrada nessa região. Porém, atualmente apenas $8 \%$ desse potencial é aproveitado (Matos et al., 2011; Lessa et al., 2015; Tolmasquim, 2016).

Entretanto, projetos hidrelétricos geram grandes impactos nas regiões em que são construídos, principalmente relacionados à saúde e à educação, os quais atingem cidades, vilas e distritos e afetam moradias e equipamentos sociais. Além disso, os projetos hidrelétricos contribuem com a especulação imobiliária, a ocupação de novas áreas e o aumento da pressão sobre o uso do solo e de recursos naturais (Tolmasquim, 2016). Essas mudanças no território ocasionadas pela implantação de Projetos de Grande Escala (PGE), como uma usina hidrelétrica, têm ganhado lugar de destaque em relação aos impactos à saúde das populações atingidas direta $\mathrm{e}$ indiretamente pelas obras (Couto, 1999; Teixeira et al., 2006; Silveira et al., 2012; Brasil, 2014; Giongo et al., 2015; Fragelli \& Oliveira, 2017).

Nessa perspectiva, a dimensão saúde ${ }^{1}$ vem ganhando espaço nas discussões acadêmicas sobre

${ }^{1}$ Considera-se aqui o conceito de saúde de acordo com a definição da Organização Mundial de Saúde (OMS): a saúde é um completo estado de bem-estar físico, social e mental. 
desenvolvimento econômico, sustentabilidade e questões sociais que envolvem PGE. Segundo Silveira et al. (2012), no processo do desenvolvimento se estabelecem novos padrões de consumo, assim como condições sociais, econômicas e culturais diferentes, e essas complexas mudanças de contextos impactam fortemente a saúde humana.

Ainda de acordo com Silveira et al. (2012), a multiplicidade de problemas socioambientais e a complexa determinação social do processo saúde-doença abrangem questões básicas, como emprego, saneamento, moradia, educação, renda e acesso aos serviços de saúde. Por isso, é necessária uma abordagem interdisciplinar, intersetorial e sistêmica que busque retratar as questões e as contradições relacionadas ao desenvolvimento, de modo que este seja compreendido em sua globalidade e que se entendam as conexões entre os impactos ambientais e as repercussões destes, tanto na saúde humana quanto na saúde pública.

Por exemplo, na fase de implantação de uma usina, um número significativo de trabalhadores de outras regiões é atraído para o local da obra em busca de emprego, novas oportunidades de negócios e desenvolvimento econômico, o que contribui para a modificação da dinâmica populacional das áreas de influência do empreendimento (Tolmasquim, 2016). Assim, assume-se que as transformações causadas nessa dinámica impactam drasticamente a saúde pública, particularmente considerando o intenso aumento da demanda nos serviços de saúde observado em situações de implantação de grandes projetos e obras de desenvolvimento (OMS, 1946; Silveira et al., 2012; Brasil, 2014). No caso da construção da Usina Hidrelétrica de Belo Monte no município de Altamira (PA), segundo o Relatório de Impacto Ambiental (RIMA) do empreendi- mento, nos primeiros cinco anos (pico das obras) estimava-se a geração de 18 mil empregos diretos e cerca de 23 mil indiretos. Depois desse tempo, o número de vagas de emprego diminuiria devido à necessidade de mão de obra apenas para serviços mais especializados (Brasil, 2009).

A experiência do Brasil em projetos e construção de UHEs mostra que, apesar do declínio de geração de oportunidades de trabalho com o fim das obras, parte da população atraída pela oportunidade de trabalho estabelece vínculos com a região e passa a residir nas áreas próximas a esses grandes empreendimentos (Neto, 2015). Tendo isso em vista, este artigo busca discutir e analisar os impactos associados ao crescimento urbano da cidade de Altamira (PA) com a construção da UHE de Belo Monte, de modo a compreender seus efeitos na saúde pública.

\section{A geração hidrelétrica na Amazônia}

Segundo Tolmasquim (2016), a capacidade instalada de usinas hidrelétricas no Brasil é de 86 GW, com geração de 359.743 GWh em 2015. Atualmente, o Brasil tem um potencial hidroelétrico de $172,3 \mathrm{GW}$, dos quais 104,6 GW são de usinas que estão em operação e $67,7 \mathrm{GW}$ de projetos hidrelétricos inventariados para serem explorados. Cerca de $66 \%$ desse potencial está localizado na região Norte, principalmente nas regiões hidrográficas Amazônica e Tocantins-Araguaia.

Portanto, em um país em que a matriz energética é eminentemente hidráulica, não é novidade que surjam novos projetos para construção de UHEs. Esses projetos são sempre cercados de polêmicas, que envolvem a resistência de ambientalistas e 
geram graves conflitos sociais (Matos et al., 2011; Giongo et al., 2015).

Pereira (2013) aponta que o enfoque dado à política energética do país para a Amazônia justifica-se pelo fato de a construção de usinas nessa região apresentar baixo custo social e econômico, principalmente por causa da disponibilidade de terras, da população escassa, do nível de atividade econômica baixa e dos solos pouco férteis. Com isso, o governo tem a intenção de atrair indústrias eletrometalúrgicas para a Amazônia, uma vez que com a construção de usinas nessa região será possível suprir a demanda energética desse setor. Desse modo, a política energética amazônica não está voltada, de fato, para a Amazônia, mas serve apenas para atender aos interesses regionais desse setor (Becker et al., 1996 apud Couto, 1999).

Devido a esses fatores, a Amazônia tem sido cenário de grandes obras de infraestrutura energética, como as hidrelétricas de Tucuruí (iniciada em 1975, no Pará), Balbina (iniciada em 1989, no Amazonas), Jirau e Santo Antônio (iniciadas em 2009, em Rondônia) e, a mais polêmica de todas, a de Belo Monte (iniciada em 2011, no entorno da cidade de Altamira, no Pará). Existem ainda projeções de que mais usinas sejam construídas nos próximos 20 anos na região amazônica (Couto, 1999; Conceição, 2014).

\section{Metodologia}

A pesquisa foi organizada em duas etapas. Primeiramente, foi realizado um levantamento de referências bibliográficas e documentais, buscando uma revisão relativa aos seguintes temas: avaliação de impacto à saúde; avaliação de impactos no meio ambiente; energia; projetos de usinas hidrelétricas e desenvolvimento urbano. A pesquisa bibliográfica abrangeu a seleção de artigos, teses e dissertações.

O levantamento documental foi realizado mediante consulta a órgãos públicos e instituições privadas e não governamentais, o que permitiu uma caracterização social, ambiental e urbana do município de Altamira, particularmente das regiões mais afetadas pelo empreendimento, como a urbana. Dos documentos consultados, destacam-se o Relatório de Impacto Ambiental (RIMA) da Usina Hidrelétrica de Belo Monte, o Plano Diretor do Município de Altamira, os dados censitários do Instituto Brasileiro de Geografia e Estatística - IBGE (1920-2010), os relatórios do Departamento de Atenção Básica do Ministério da Saúde, assim como os relatórios de organizações não governamentais. A sistematização deste levantamento e da revisão da literatura permitiu o confronto com o debate acerca dos grandes projetos de desenvolvimento na região amazônica, fundamentando a discussão sobre a matriz de energética no Brasil, os impactos e efeitos socioambientais de obras de grande porte em regiões como a amazônica, repletas de vulnerabilidades.

\section{Impactos da UHE de Belo Monte}

\subsection{Breve histórico de ocupação de Altamira}

Como mostra a Figura 1, a cidade de Altamira está localizada na região amazônica, no Estado do Pará, e teve uma população estimada de aproximadamente 111.435 habitantes em 2017 (IBGE, 2017). Altamira começou a se desenvolver no início da década de 1970, com o Plano de Integração 
Nacional (PIN), que construiu estradas na floresta tropical, promoveu a colonização por agricultores e fomentou a extração de recursos e o desenvolvimento da pecuária. Os objetivos dos projetos de colonização foram desenvolver o interior do país, aliviar a pressão pela posse de terra e a pobreza na região Nordeste, que sofria - e sofre - com a seca, e reassentar posseiros e pequenos agricultores do Sul do Brasil (Randell, 2016).
Como parte do PIN, o governo construiu a Rodovia Transamazônica (BR-230), que atravessa Altamira conectando a região Norte com a região Nordeste. Como consequência, esse projeto de desenvolvimento resultou no crescimento da população do Estado do Pará durante as décadas de 1970 a 1996 (de 2,2 milhões para 5,5 milhões), decorrente da forte migração para essa região incentivada pelo governo (Randell, 2016).

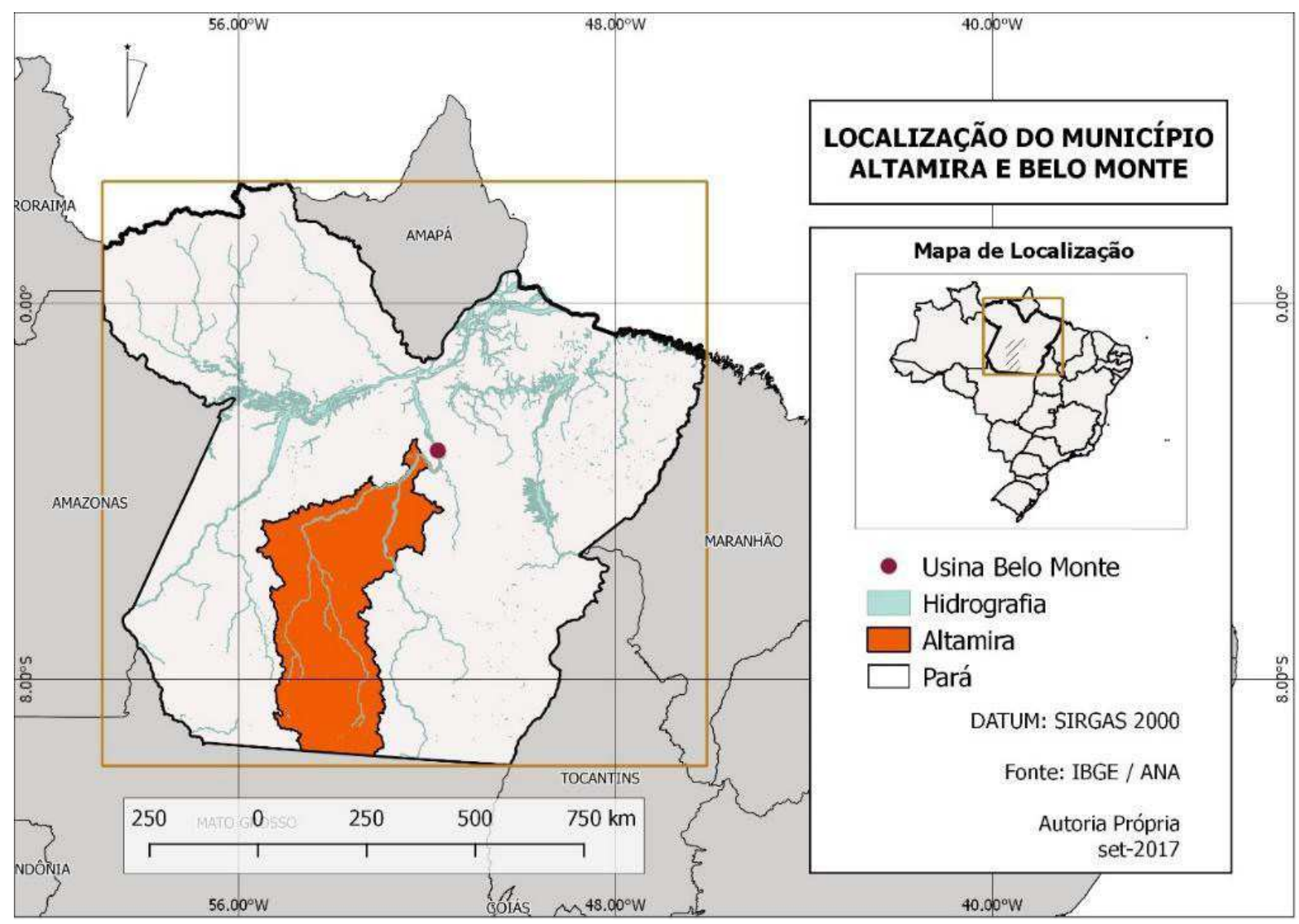

FIGURA 1 - Localização da cidade de Altamira e da Usina de Belo Monte

FONTE: Elaborado pelos autores com base nos dados do IBGE/ANA (2017). 
Os centros urbanos próximos a Altamira (Pacajá, Anapu, Brasil Novo, Medicilândia e Uruará) têm suas sedes ligadas diretamente pela Rodovia Transamazônica (BR-230). Já Vitória do Xingu tem acesso a Altamira pela PA-415, ficando apenas os núcleos de Senador José Porfírio e Porto de Moz interligados por meio do Rio Xingu. Assim, Altamira se consolida como núcleo urbano da região (Neto \& Herrera, 2016; Randell, 2016). A evolução populacional urbana e rural do município de Altamira entre os anos de 1920 e 2010 registrou um aumento expressivo, principalmente na população urbana entre 1960 e 1980, conforme pode ser observado na
Figura 2, elaborada com base nos censos históricos e nas estimativas populacionais do IBGE.

Essa taxa de crescimento, nessa região foi a maior do país. Isso é reflexo das modificações estruturais da região, em que o povoamento passou a ser ao longo das rodovias, e não mais ao longo da rede fluvial, o que facilitou a mobilidade espacial, com elevada migração e frequente expropriação da terra, ligada a um processo de urbanização segregador (Becker, 2005).

De 1996 até 2000, ocorreu uma acentuada redução da população rural. Segundo Fernandes et al. (2009), nos anos 1990, a região foi marcada por um

\section{Evolução Populacional de Altamira (1920 - 2010)}

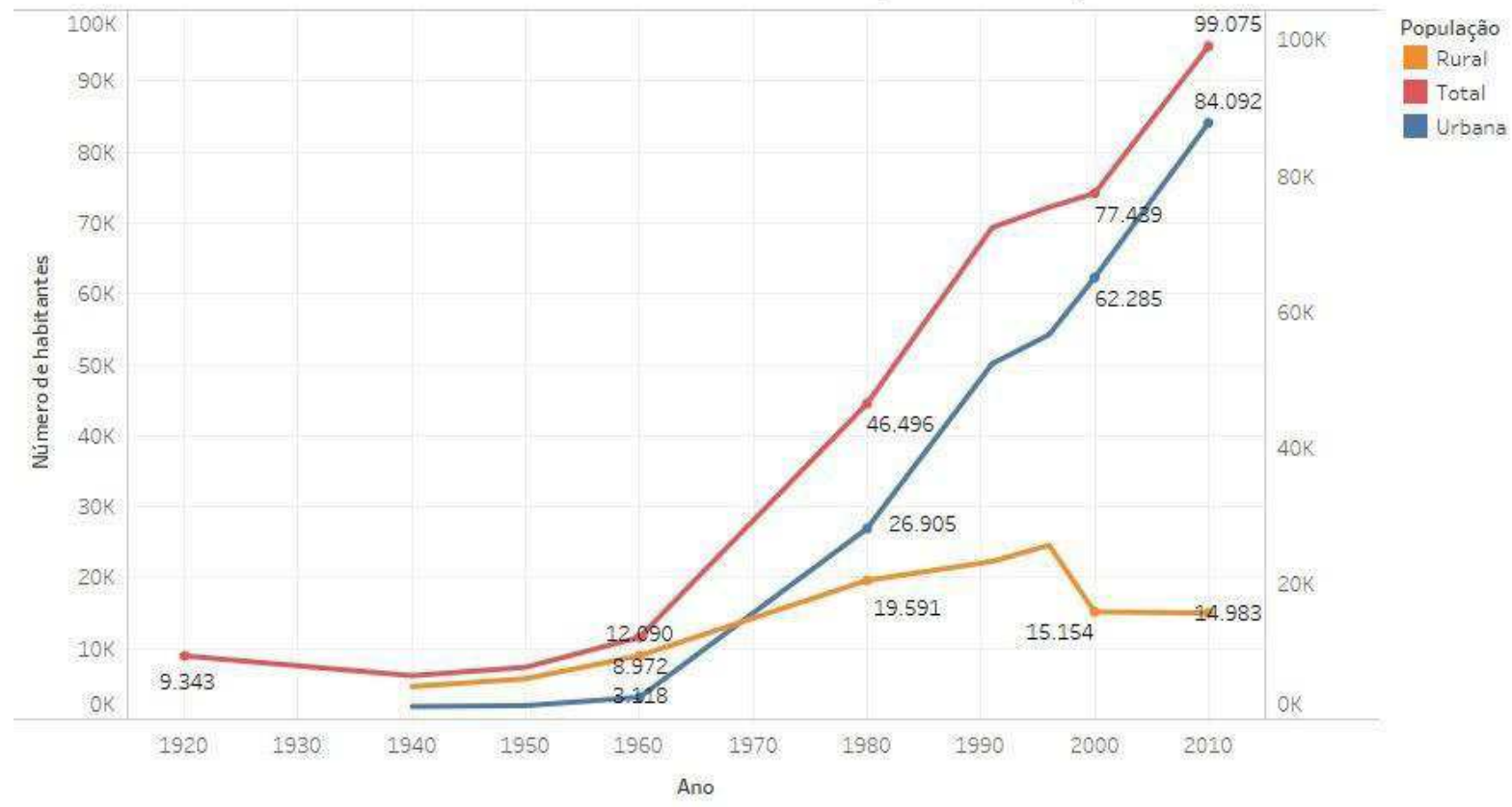

FIGURA 2 - Gráfico da evolução populacional do município de Altamira (1920-2010).

FONTE: Elaborado pelos autores com base no IBGE (1920-2010). 
crescimento desacelerado, com perda de dinamismo econômico e populacional, o que intensificou o processo de mobilidade do homem do campo para a cidade, dentro e fora da região, consolidando o êxodo rural.

Segundo o último levantamento realizado pela Secretaria de Planejamento do Município, a população total de Altamira é de 148.224 mil habitantes, o que representa, somente na área urbana, cerca de 127 mil pessoas, ou seja, uma taxa de crescimento acima do esperado (Neto, 2015).

\subsection{O projeto Belo Monte e as mudanças no espaço urbano de Altamira}

A Norte Energia, parceria público-privada, está construindo o Complexo Hidrelétrico de Belo Monte. Os planos para a barragem começaram na década de 1970, mas sofreram atrasos devido à preocupação com seus impactos socioambientais. O projeto ganhou impulso no governo do ex-presidente Luís Inácio Lula da Silva (Randell, 2016).

$\mathrm{O}$ Estado brasileiro resgatou esse assunto e colocou a construção da UHE de Belo Monte como obra estratégica para o desenvolvimento econômico do país e como uma das alternativas para resolver a crise energética do Brasil. O projeto foi remodelado para tornar-se mais aceitável aos ambientalistas e movimentos sociais, e sua principal mudança foi a diminuição do reservatório da usina (Fleury \& Almeida, 2013; Randell, 2016).

A construção teve início em 2011 e tem previsão de término em 2019. A área a montante da barragem foi inundada no início de 2016, quando a primeira turbina começou a operar. De acordo com o RIMA do empreendimento, a barragem deverá inundar $516 \mathrm{~km}^{2}$ de terra e reassentar cerca de 20 mil pessoas, porém ambientalistas afirmam que o número real de reassentados poderia ser de até 40 mil (Magalhães \& Hernandez, 2009; Brasil, 2009).

Com o início das obras, inaugurou-se uma nova fase em Altamira. Tudo começou a se estruturar para dar as condições à concretização do empreendimento. Com o aumento populacional no centro urbano, um número grande de empresas se instalou no município, muitas visando atender às necessidades da construção da usina, principalmente relacionadas ao setor de construção e serviços. Entre 2011 e 2013, chegaram à cidade um total de 45.934 funcionários contratados para trabalhar na obra. Destes, “[...] 101 executivos, 1.814 ligados a escritório e 44.019 voltados às obras" (Neto, 2015, p. 2508).

Caso semelhante aconteceu na construção da Usina de Tucuruí, também no Estado do Pará, em 1975, que teve um fluxo migratório de aproximadamente 30.200 pessoas, principalmente de trabalhadores de outras regiões do país em busca de emprego. Estudos apontam que a construção de usinas hidrelétricas mobiliza milhares de pessoas que migram para os locais de construção, provocando modificações socioeconômicas e ambientais nas comunidades (Conceição, 2014). No caso de Altamira, a previsão do RIMA de Belo Monte é de que, ao longo do período de construção da usina, cheguem cerca de 96 mil pessoas à região (Brasil, 2009).

Diante da expectativa criada com a implantação da UHE, o Plano Diretor Municipal de Altamira, elaborado em 2003, foi revisado em 2010 pela TECHNUM Consultoria, que estabeleceu metas de crescimento com base nos projetos futuros de expansão econômica da região (agroindústria, 
mineração e a usina) e elencou seus pontos fortes e fracos e as ameaças e as oportunidades a serem melhoradas. Nessa revisão considerou-se principalmente os impactos ambientais, sociais e econômicos apontados no Estudo de Impacto Ambiental (EIA) e no RIMA de Belo Monte. Bem como as modificações provenientes da ocupação do espaço urbano antes, durante e após a construção da usina (Altamira, 2010).

Entretanto, Magalhães \& Hernandez (2009) alertam que o EIA e o RIMA de Belo Monte apresentam vários problemas. Entre eles, podem ser citados os seguintes: inconsistência metodológica; ausência e falhas nos dados; ausência de referencial bibliográfico adequado; uso de retórica para ocultar impactos; negligência na avaliação dos riscos à saúde; subdimensionamento da área diretamente afetada; subdimensionamento dos custos social, econômico e ambiental; ocultação dos impactos às terras indígenas próximas a jusante da usina (Volta Grande do Rio Xingu); entre outros problemas (Corrêa, 2016).

Essa situação apresenta indícios de que a elaboração do Plano Diretor baseado nos EIA-RIMA compromete as políticas de desenvolvimento urbano de Altamira, pois estas não conseguirão representar a realidade local, principalmente pela nova dinâmica social e econômica do município em relação às obras desse empreendimento. Nesse sentido, Ribeiro \& Cardoso (2003) fazem uma crítica sobre as tendências em que o planejamento urbano brasileiro vem se estruturando, principalmente pela crescente visão tecnicista. Para os autores, isso reflete na maneira como são encarados os problemas sociais gerados por um processo de urbanização regido pelo sistema capitalista, que, ao longo de décadas, apresentou forte relação com a segregação social e a maneira de ocupação do espaço urbano desigual. Com isso, o que se tem é um Plano Diretor que legaliza e respalda o Estado a prosseguir com sua política de desenvolvimento e, atrelado ao acúmulo do capital, proporciona segregação e conflitos sociais.

No que se refere às políticas de desenvolvimento urbano em regiões com projetos hidrelétricos, como no caso de Altamira, tenta-se atribuir no imaginário da população que esses empreendimentos são projetos de desenvolvimento local, mas, na verdade, são apenas padrões repetitivos de construção que propagam formas urbanas estranhas e reproduzem uma lógica segregativa na cidade. Esse padrão foi evidente na cidade de Tucuruí, que apresentou multiplicação da população, proliferação de novos assentamentos (planejados ou não), densidade da ocupação urbana com multiplicação da malha urbana, além da ampliação das desigualdades (Neto, 2015).

Em Altamira, as interferências do projeto da UHE de Belo Monte estão, "[...] rapidamente, remodelando a forma urbana e engendrando uma reestruturação da cidade" (Neto, 2015, p. 2505). Diante disso, é proposto pelo EIA-RIMA o Plano de Requalificação Urbana, que é um conjunto de ações para as cidades afetadas pela construção e pela operação da UHE de Belo Monte, com os objetivos de atender às necessidades da população realocada e integrar as residências dos funcionários da obra até as cidades de Altamira e Vitória do Xingu (Brasil, 2009). Para amenizar os impactos na área urbana, a Norte Energia prevê a construção de cerca de 12 mil novas unidades habitacionais em Altamira e de cinco novos bairros (Água Azul, Casa Nova, São Joaquim, Laranjeiras e Jatobá), para reassentar as 
famílias devido à construção da barragem (Norte Energia, 2014; Negrão et al., 2015).

Conforme a Figura 3, que mostra a evolução da malha urbana de Altamira, elaborada por Neto (2015), entre 2010 e 2014 ocorreu uma rápida ampliação da malha urbana do município, assim como do crescimento do perímetro urbano - de $95,235 \mathrm{~km}^{2}$ para $111,229 \mathrm{~km}^{2}$. Essas modificações são reflexos das medidas mitigadoras elaboradas pelo consórcio Norte Energia, juntamente com o crescimento demográfico.

Segundo Neto (2015), tais mudanças alteram intensamente a estrutura da cidade, modificando o padrão de localização residencial, pois mais de 22 mil pessoas estão sendo removidas das áreas próximas aos leitos dos rios e sendo realocadas. A ampliação da malha urbana ocorreu principalmente pela oferta de 22.168 lotes urbanos distribuídos em cinco loteamentos, os quais compreendem 708,19 hectares, o que atraiu grandes empresas do setor imobiliário. Referente às habitações de interesse social, foram projetados dois loteamentos para Altamira: os conjuntos residenciais Ilha do Arapujá e Santa Benedita, com 1.444 e 958 lotes, respectivamente. Todos esses loteamentos representam um crescimento de $50 \%$ da malha urbana em relação a 2010 e, consequentemente, sua periferização.

Nesse contexto, o planejamento urbano é pensado como ferramenta de desenvolvimento, e o Estado investe na construção de conjuntos habitacionais, acreditando que apenas isso é suficiente para resolver os problemas sociais e mostrando total despolitização do processo de urbanização. Algo parecido ocorreu nos empreendimentos do Programa

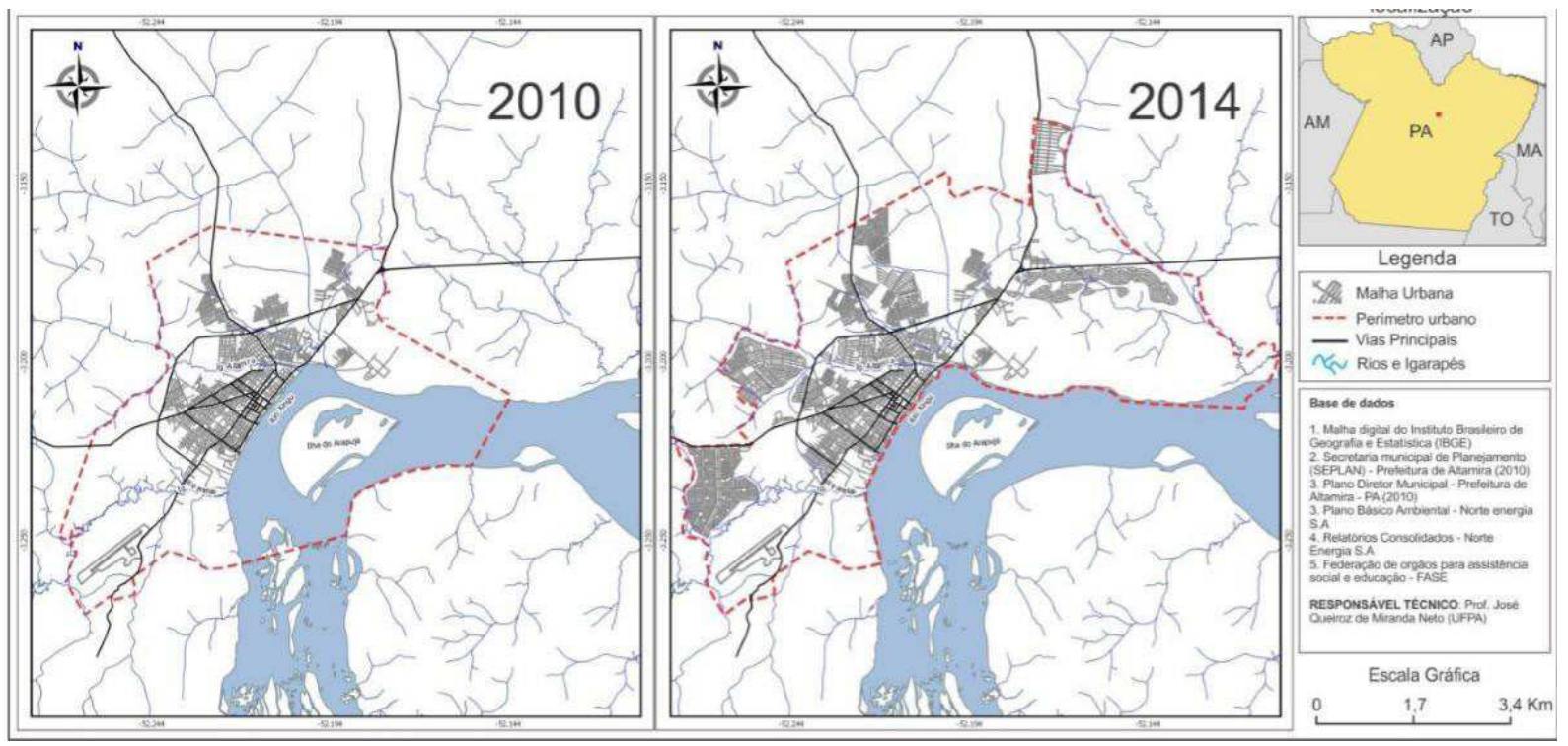

FIGURA 3 - Mapa com a evolução da malha urbana de Altamira (PA), no período de 2010 a 2014.

FONTE: Neto (2015). 
Minha Casa, Minha Vida, em que a localização de conjuntos habitacionais - muitas vezes isolados dificulta a mobilidade urbana e o acesso a serviços públicos básicos, como educação e saúde (Ribeiro \& Cardoso, 2003; Negrão et al., 2015).

Diante disso, para um melhor planejamento das áreas urbanas de um município e. consequentemente, melhor regulação do uso e da ocupação do solo, é instituído o zoneamento ambiental, instrumento de gestão socioambiental importante e amplamente utilizado na elaboração dos planos diretores. Esse instrumento permite a divisão da cidade em áreas que receberão diretrizes diferenciadas, visando, por exemplo, ao controle do crescimento urbano e do tráfego de automóveis e à proteção de áreas inadequadas à ocupação urbana (Saboya, 2007; Barbosa \& Carvalho, 2010). No zoneamento são definidas as áreas da cidade que terão usos industriais, comerciais, residenciais e áreas mistas.

O Plano Diretor de Altamira instituiu em seu zoneamento urbano 12 zonas, que se dividem
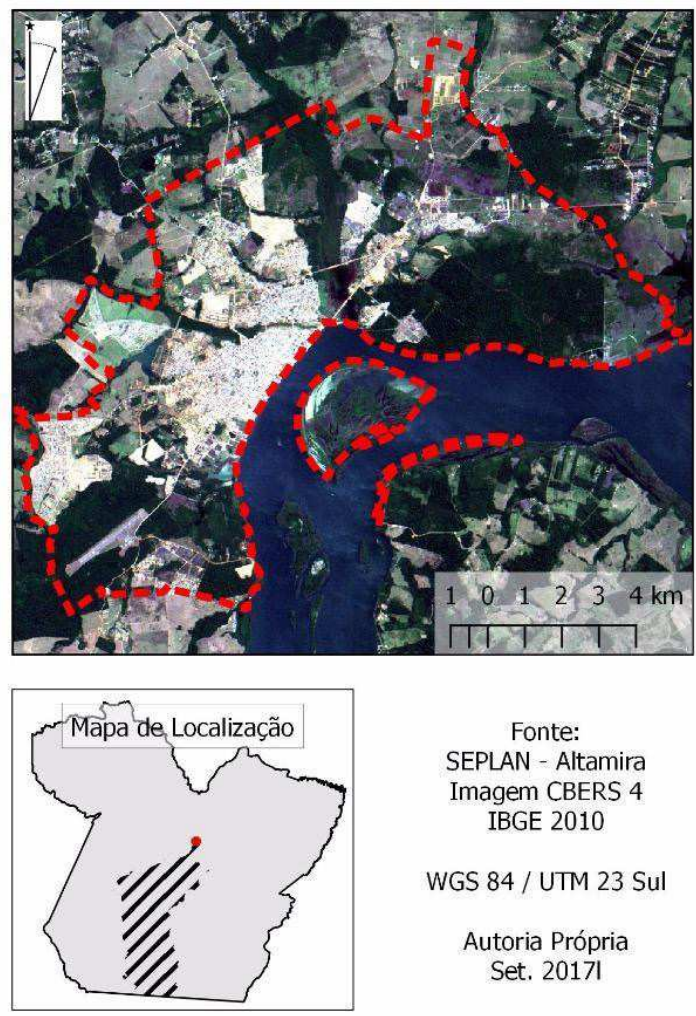

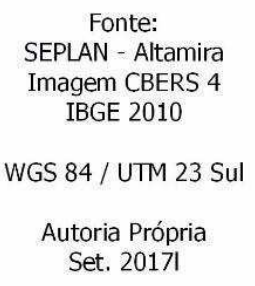

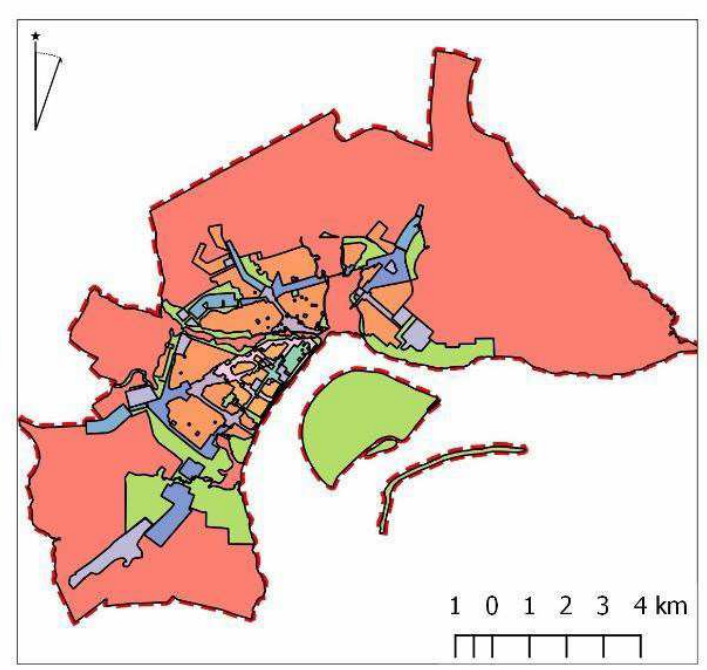

Zoneamento Urbano
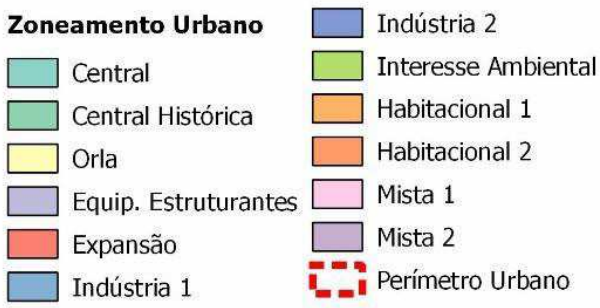

FIGURA 4 - Zoneamento urbano do município de Altamira.

FONTE: Elaborado pelos autores com base nos dados vetoriais fornecidos pela Prefeitura de Altamira e com imagem do satélite CBERS 4 (2017). 
entre zonas centrais, de carácter histórico, mistas, habitacionais, de interesse ambiental, industriais, equipamentos estruturantes e a chamada Área de Expansão Urbana, conforme podem ser visualizadas na Figura 4. Os mapas da Figura 4 foram elaborados com informações cedidas pela Secretaria de Planejamento de Altamira (SEPLAN) e com uma imagem do Satélite CBERS 4, capturada em julho de 2017.

A área de expansão urbana de Altamira definida pelo zoneamento, conforme apresentado na Figura 4, não tem uma frente de expansão bem definida, com um vetor de crescimento direcionado para um único sentido, mas compreende toda uma borda de expansão nos limites do perímetro urbano, prevendo um espalhamento da cidade para todos os lados em que o crescimento urbano é possível. São mais de $78 \mathrm{~km}^{2}$ destinados ao crescimento urbano, o que corresponde a $66 \%$ de todo o zoneamento delimitado e representa uma área maior que todas as outras zonas somadas.

Nesse sentido, o município de Altamira, ao instituir em seu zoneamento uma zona de expansão urbana de mais de $78 \mathrm{~km}^{2}$, não apenas prevê, como também estimula um adensamento populacional em toda essa área.

\subsection{O crescimento populacional e sua relação com a saúde}

A construção de hidrelétricas tem se estabelecido historicamente como um campo de lutas, violência e intensos jogos de poder, pois esses empreendimentos modificam não apenas o espaço territorial das populações atingidas, mas suas histórias, suas condições de trabalho e o modo de organização social e política. Esses impactos estão diretamente relacionados aos efeitos no processo de saúde e ao adoecimento das populações inseridas nesses ambientes (Zhouri \& Oliveira, 2007; Silveira \& Araújo Neto, 2014; Giongo et al., 2015).

A realização de projetos de desenvolvimento no Brasil, até a década de 1980, estava ligada apenas às avaliações econômicas e técnicas e não considerava os impactos ambientais e os interesses públicos referentes às obras. Com a Lei n. 6.938/1981, que trata da Política Nacional de Meio Ambiente (PNMA), o Brasil passou a exigir o licenciamento ambiental. Porém, somente com a publicação da Resolução n. 001, de 23 de janeiro de 1986, o Conselho Nacional do Meio Ambiente (Conama) estabeleceu as definições, as responsabilidades, os critérios e as diretrizes gerais do uso do EIA. O órgão também estabeleceu o respectivo EIA-RIMA, tornando-o vinculado ao licenciamento ambiental. O EIA-RIMA é um dos instrumentos da PNMA para assegurar a realização da Avaliação de Impacto Ambiental (AIA), cujos objetivos são os seguintes: certificar que os aspectos ambientais sejam incorporados e debatidos ao processo deliberativo; prever os efeitos negativos para minimizá-los ou evitá-los; defender a capacidade de produtividade dos sistemas naturais e processos ecológicos a conservar suas funções; favorecer o desenvolvimento sustentável e aperfeiçoar a gestão e o uso dos recursos (Brasil, 1981; CONAMA, 1986; Sánchez, 2013; Giongo et al., 2015; IBAMA, 2017; Abe, 2017).

Entretanto, os EIAs são insatisfatórios no que tange aos impactos na saúde durante a construção de uma UHE, na medida que os problemas na saúde são encarados como resultados secundários do impacto ambiental. Silveira \& Araújo Neto (2014) evidenciam alguns elementos que estão relacionados a essa situação: baixa participação dos órgãos 
da saúde no processo de licenciamento ambiental; exigência de participação desses órgãos direcionada apenas para algumas regiões do Brasil; problemas metodológicos quando é preciso estabelecer critérios específicos para a avaliação dos impactos à saúde e das pressões sofridas pela liberação rápida das obras. Assim, as questões associadas à saúde ainda são tratadas como secundárias e incapazes de ser condicionantes ao licenciamento ambiental. $\mathrm{O}$ que se percebe são ações mitigadoras e compensatórias, tardiamente implementadas, visando apenas suavizar os efeitos dos impactos na saúde pública.

Essa situação é um problema que vem sendo questionado em estudos recentes por várias pesquisadoras ligadas ao tema, como Abe (2017) e Silveira (2016). Ambas enfatizam que, apesar de o licenciamento ambiental considerar os efeitos na saúde humana decorrentes dos impactos ambientais de empreendimentos potencialmente poluidores, esse aspecto é incipiente ou muitas vezes negligenciado durante sua avaliação. Esse fator está relacionado, segundo as autoras, pela falta de regulamentação que institucionalize a participação do setor saúde no processo de licenciamento ambiental. Na legislação brasileira existe apenas uma exceção sobre a incorporação da saúde na AIA de empreendimentos potencialmente poluidores, que é o monitoramento da malária. Este consiste em um mecanismo legal que regulamenta a participação da saúde no processo de licenciamento ambiental, nas regiões endêmicas para projetos de assentamento de reforma agrária e outros empreendimentos na região amazônica (CONAMA, 2001; Brasil 2006). Entretanto, para outros determinantes de saúde não existe legislação ou diretrizes específicas articuladas ao licenciamento ambiental, o que impede uma abordagem sistêmica sobre as questões de saúde (Abe, 2017).
Diante disso, o Ministério da Saúde lançou o guia Avaliação de Impacto à Saúde (AIS): metodologia adaptada para aplicação no Brasil, ferramenta baseada na discussão realizada pela OMS em alguns países desenvolvidos, que estabeleceu critérios e a organização das etapas para esse tipo de avaliação (Brasil, 2014). Como essa metodologia só foi adaptada e publicada pelo Ministério da Saúde em 2014 e não há uma legislação que regulamente sua utilização, essa avaliação ainda é pouco difundida e utilizada.

Giongo et al. (2015) apontam que o primeiro problema de saúde relacionado à construção de uma UHE se inicia com a chegada de um grande número de trabalhadores da construção civil, que vêm em busca de trabalho na obra. São trabalhadores sazonais que circulam por território nacional e, muitas vezes, carregam consigo doenças como tuberculose, sífilis, HIV/Aids, entre outras. As autoras também ressaltam que esses trabalhadores são vítimas das condições de trabalho insalubres e perigosas, pois, na maioria dos casos, são disponibilizados alojamentos temporários em condições precárias pelos empreendedores, o que deixa esses trabalhadores expostos às mais diversas formas de violência e restrições dos direitos sociais. Os acidentes e as mortes também fazem parte desse cenário, tornado invisível ao olhar da sociedade.

No caso de Altamira, o principal impacto na saúde pública apontado por Fragelli \& Oliveira (2017) é em relação ao perfil da população retratado no Censo de 2010. Isso porque as ações referentes à saúde pública no Brasil, bem como à elaboração de políticas públicas de atenção e financiamento do Sistema Único de Saúde (SUS), são regidas pelo Censo Demográfico, realizado pelo IBGE. O censo consegue retratar um diagnóstico profundo 
da população brasileira, em suas características socioeconômicas, direcionando todo o planejamento público e privado para a década seguinte. Assim, se os dados estiverem comprometidos, não será possível traçar um planejamento eficiente para o território em análise.

O último censo populacional realizado no Brasil foi em 2010, período em que Belo Monte recebeu a Licença Prévia (LP 342/2010). Em 2011, a usina recebeu a Licença de Instalação (LI 795/2011), o que marcou o início das transformações violentas no território, devido à sua construção, assim como a chegada de um grande número de pessoas no município por causa do início das obras. Dessa forma, um significativo aumento populacional fora da curva regular de crescimento e migração passou a corroborar sérias consequências à saúde pública do município (Fragelli \& Oliveira, 2017).

No que tange à assistência à saúde, a atenção básica foi negativamente impactada, visto que o quantitativo de equipes de saúde da família (eSF) não se equipara ao aumento populacional do período. Para Malta et al. (2016), a atenção básica é considerada uma importante porta de entrada do SUS e é o primeiro contato da população com os serviços de saúde. Portanto, cabe à atenção básica não apenas a redução das taxas de internação e a melhoria nos indicadores, mas também a redução de desigualdades socioeconômicas e o aumento da qualidade de vida da população. Assim, é necessário que sua promoção seja garantida de maneira universal.

O princípio da universalidade exprime a ideia de que o Estado tem o dever de prestar atendimento à saúde de toda a população brasileira (Pontes et al., 2009). Nesse sentido, a Constituição Federal de 1988, em seu art. 196, estabelece que é dever do Estado garantir a promoção, a proteção e a recuperação da saúde a todos os brasileiros, por meio de políticas sociais e econômicas que objetivem a redução do risco de doenças e de outros agravos, permitindo a promoção universal às suas ações e seus serviços (Brasil, 1988).

Cardoso \& Vieira-da-Silva (2012) afirmam que a universalização da atenção à saúde tem sido associada aos direitos das pessoas à cidadania. Essa universalização compreende a cobertura da assistência à saúde e não pode ser confundida por acesso à saúde. É preciso compreender que acesso e cobertura são dois conceitos relacionados, porém diferentes. O acesso à saúde está ligado a variáveis específicas, como condições de vida das pessoas, acessibilidade do usuário ao serviço, horário do atendimento, tempo e custo do deslocamento, entre outras. A complexa teia de fatores relacionados vai além da dimensão geográfica e da oferta de saúde, dificultando a operacionalização de análises mais profundas sobre o acesso (Ramos \& Lima, 2003). Já a cobertura compreende a disponibilidade e a distribuição social das unidades de saúde, ou seja, analisa a proporção dos serviços de assistência diante da demanda (Cardoso \& Vieira-da-Silva, 2012). Dessa forma, optou-se por avaliar neste artigo a cobertura da assistência à saúde em Altamira, medida pela proporção de eSF.

$\mathrm{Na}$ atenção básica, a Estratégia de Saúde da Família (ESF) é considerada política prioritária da universalização da saúde e funciona por meio de eSF. A Política Nacional da Atenção Básica PNAB, efetiva até 2017, período analisado neste artigo, descreve como deve ser a composição da eSF: um médico, um enfermeiro, um auxiliar de enfermagem, pelo menos quatro agentes comunitários de saúde, além de profissionais de saúde bucal. 
Essa política evidencia ainda que as eSF devem atuar em áreas geograficamente delimitadas, com populações adstritas de até 4 mil pessoas para cada equipe ( 3 mil é a média recomendada). Esse número pode diminuir conforme o risco e a vulnerabilidade social da população (Brasil, 2012).

Entretanto, a Portaria n. 2.436 revisou as diretrizes da PNAB em 21 de setembro de 2017. Com isso, a eSF passou a ter uma população adscrita de 2 mil a 3.500 e deve ser composta pela mesma equipe recomendada pela PNAB 2012. Entretanto, o número de agentes comunitários de saúde (ACSs) por equipe passou a ser definido de acordo com a quantidade populacional, a demografia da região e os fatores epidemiológicos e socioeconômicos.
Além disso, para áreas de grande dispersão territorial e de risco e vulnerabilidade social, a cobertura indicada é 100\% da população (Brasil, 2017).

A Figura 5 apresenta a comparação da cobertura populacional estimada por eSF entre o município de Altamira, o Estado do Pará e o Brasil, durante os anos de 2007 a 2017. Os dados coletados são disponibilizados mensalmente na plataforma online do Departamento da Atenção Básica do Ministério da Saúde. Todavia, foram considerados para este artigo apenas os dados do mês de julho de cada ano, visto que é o mês de atualização anual da estimativa populacional do IBGE.

Após 2011, ano da liberação da licença de instalação de Belo Monte e período de intenso fluxo

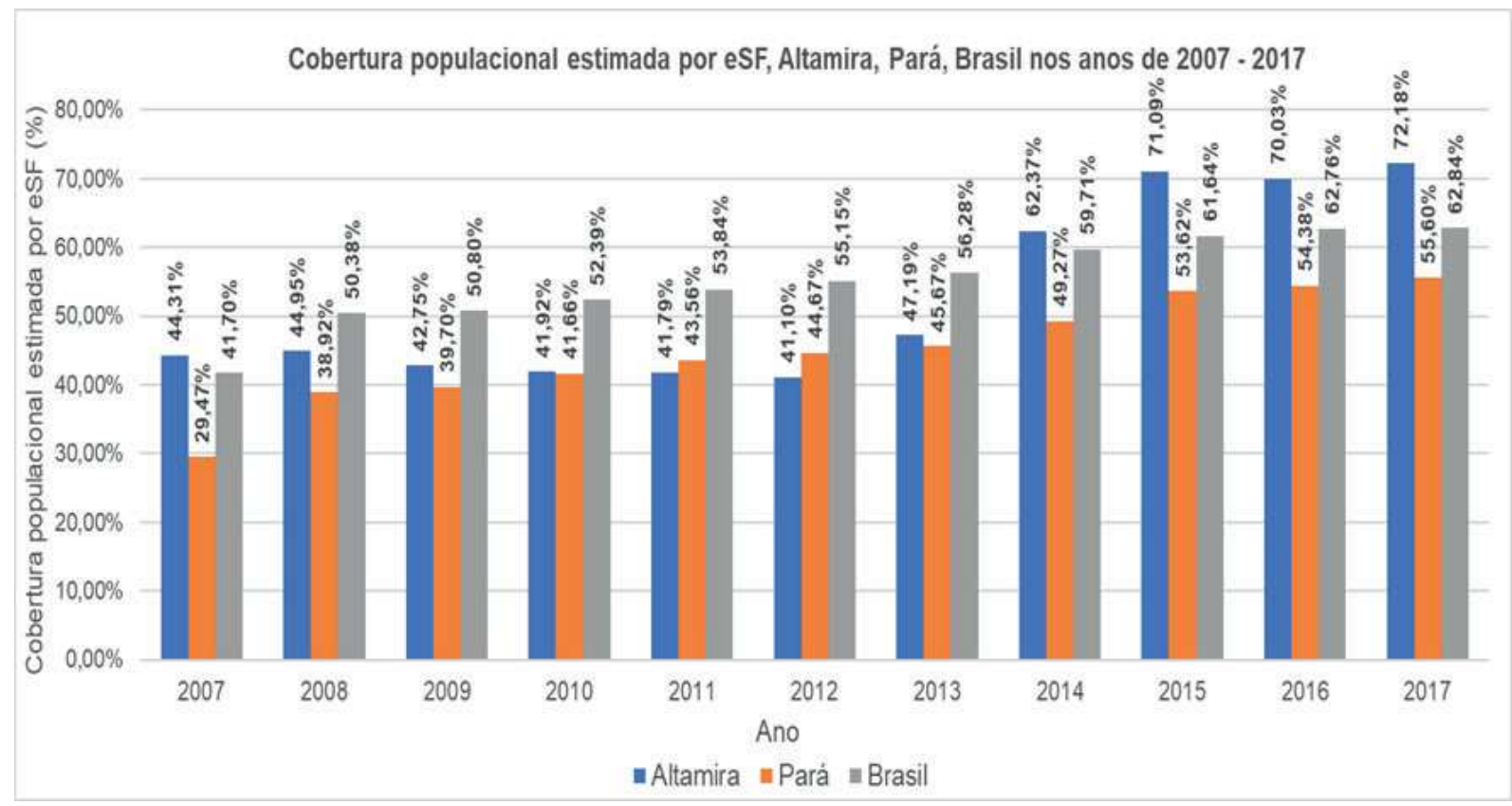

FIGURA 5 - Cobertura populacional estimada por eSF no município de Altamira, no Estado do Pará e no Brasil nos anos de $2007-2017$. FONTE: Ministério da Saúde/E-Gestor Atenção Básica: Informação e Gestão da Atenção Básica (2018). 
migratório para região, a cobertura da eSF, que já era baixa, teve seu pior resultado, apresentando em 2012 uma taxa de apenas $41,1 \%$, o que representa cobertura de apenas 41.400 pessoas no período (Figura 5). Contudo, nos anos seguintes, ocorreu um aumento significativo na cobertura, que passou de $47,2 \%$, em 2013, para $72,2 \%$ em 2017. Além disso, os resultados para o Estado do Pará e para todo o Brasil não sofreram diminuição nas taxas no período de 2010 a 2012; pelo contrário, ambos apresentaram taxas continuamente crescentes de cobertura: o Pará passou de 29,47\%, em 2007, para $55,60 \%$ ao fim do período de 10 anos, e o Brasil passou de 41,70\%, em 2007, para 62,84\% em 2017. É possível ainda observar que Altamira apresenta taxas bem superiores a partir de 2014 se comparada ao Pará e ao Brasil.

Os dados encontrados para o período de início das obras de Belo Monte em Altamira têm a mesma explicação evidenciada por Cardoso \& Vieira-da-Silva (2012). Diante da baixa cobertura da atenção básica em Salvador, para os autores as baixas taxas são, portanto, reflexos do crescimento insuficiente da oferta de serviços perante o aumento na demanda assistencial e decorrem da baixa expansão da rede de atendimento do município, em particular das eSF.

A taxa atual de cobertura do município não contempla toda a população e encontra-se distante de alcançar $100 \%$ do município. Todavia, a Figura 5 demonstra que Altamira teve uma alta cobertura nos últimos anos se comparada ao Estado do Pará e ao Brasil. O que chama atenção, entretanto, é o fato de que quanto mais distante do período de realização do censo, mais contestáveis são os dados populacionais de uma região em relação à implantação de um PGE, como a UHE de Belo Monte, em virtude das rápidas transformações ocorridas no território
(Teixeira et al., 2006; Brasil, 2014; Fragelli \& Oliveira, 2017)

Assim, apesar da elevada taxa de cobertura encontrada no município de Altamira em relação ao Estado do Pará e ao Brasil, o possível subdimensionamento populacional reflete em taxas não condizentes com a realidade. Conforme afirmam Fragelli \& Oliveira (2017), as informações trazidas pelo Censo 2010 não retrataram de maneira fidedigna as características populacionais da região de Altamira, devido às intensas transformações ocorridas após sua realização, problematizando dessa maneira a estimativa populacional para os anos seguintes. As autoras também afirmam que

\begin{abstract}
É possível antever a dificuldade inerente à articulação entre financiamento de operações e retratos de territórios realizados em um espaço de tempo de dez anos. E por esse motivo há instrumentos disponíveis a serem construídos para mitigar esses efeitos, e que podem ser utilizados com alguma segurança, na condição de que as transformações territoriais obedeçam a uma lógica padrão de acontecimento e desenvolvimento. A amplitude da transformação territorial nesta região do Xingu, por sua vez, não pode ser alcançada pelos instrumentos em uso no Brasil hoje. (Fragelli \& Oliveira, 2017, p. 207)
\end{abstract}

Essa situação afeta toda a população de Altamira, pois a principal dificuldade é ter um diagnóstico real e objetivo das transformações ocorridas no campo da saúde antes e depois de Belo Monte. O censo é um instrumento importante para isso e não se reduz apenas a contar a população e dividi-la por sexo, faixa etária ou taxa migratória. O censo descreve quem somos e como estamos vivendo, ultrapassa a abrangência quantitativa e traz elementos significativos para análise de vários 
aspectos da saúde, pois retrata o estilo de vida das pessoas (IBGE, 2010; Fragelli \& Oliveira, 2017).

Fragelli \& Oliveira (2017) afirmam que atualmente qualquer avaliação de impactos na saúde na região atingida por Belo Monte utiliza dados produzidos no ano de 2010, após as transformações que ocorreram no território. Dessa forma, para superar isso, é necessário realizar uma avaliação que utilize instrumentos de pesquisa que apresentem as condições de vida atuais da população no território impactado pelo empreendimento.

\section{Considerações finais}

Foi possível verificar que, com o início da construção da UHE de Belo Monte em Altamira, ocorreram modificações estruturais na cidade, seja do ponto de vista social, econômico ou ambiental. A recente dinâmica da cidade é totalmente diferente daquela vista ao longo do período de estagnação econômica e de crescimento populacional na década de 1990. As mudanças são percebidas principalmente pelo aumento do fluxo populacional, ocasionado pelas oportunidades de emprego com a construção do empreendimento. Esse crescimento eleva a demanda pelos serviços públicos oferecidos pela cidade, principalmente no que tange aos serviços de saúde, uma vez que o principal problema está relacionado ao subdimensionamento dos dados censitários, que reflete diretamente na elaboração de políticas pública em saúde para região e no financiamento do SUS.

Vale ressaltar que as obras ainda não foram finalizadas e que esse complexo processo de transformação tende ainda a perdurar mesmo após o término da construção. Como o fenômeno analisado é um processo que está em curso, as pesquisas sobre ocupação urbana de Altamira são escassas, tornando-se um entrave para compreender questões mais profundas sobre a expansão urbana do município. Somente com a realização de um novo censo será possível traçar um diagnóstico mais preciso sobre todas as transformações ocorridas no território de Altamira. Entretanto, a tendência de aumento populacional em regiões com empreendimentos hidrelétricos que resultam em segregação socioespacial é percebida claramente em Altamira.

Com base na revisão e nas análises realizadas, pode-se sistematizar algumas proposições a título de recomendações para o aperfeiçoamento das políticas públicas envolvendo a construção de projetos hidrelétricos. Recomenda-se que seja incorporada a necessidade de realização da AIS para o caso de empreendimentos de médio e grande porte no país, particularmente na região amazônica; que os repasses federais para os municípios com taxas elevadas de crescimento populacional, impactados por PGEs, não dependam da medição censitária realizada a cada dez anos (para isso seria importante tornar obrigatório a realização da contagem da população nesses municípios impactados, principalmente nos primeiros anos após o início da construção de uma UHE); que o empreendedor e os governos, as esferas Federal, Estadual e municipal, responsabilizem-se por promover políticas públicas eficientes e que contemplem a participação das comunidades afetadas; que a ferramenta avaliação de impacto em saúde sugerida e publicada pelo Ministério da Saúde seja incorporada no processo do licenciamento ambiental de empreendimentos potencialmente poluidores, principalmente de hidrelétricas. Além disso, recomenda-se o aprofundamento nos estudos de viabilidade de pequenas e médias cen- 
trais hidrelétricas, assim como outras alternativas de geração menos impactantes do ponto de vista socioambiental e de saúde pública.

\section{Agradecimentos}

Os autores agradecem à Coordenação de Aperfeiçoamento do Ensino Superior (CAPES), ao Conselho Nacional de Desenvolvimento Científico e Tecnológico (CNPq) e à Universidade Federal do ABC (UFABC) por sua colaboração no desenvolvimento deste artigo.

\section{Referências}

Abe, K. C. Análise da metodologia de avaliação de impacto à saúde no brasil com enfoque a grandes empreendimentos e politicas públicas. São Paulo, Tese (Doutorado em Gestão e Informática em Saúde) - UNIFESP, 2017

ANA-Agência Nacional de Águas. Massas d'Água, 2017. Disponível em: <http://metadados.ana.gov.br/geonetwork/ srv/pt/main.home>. Acesso em 29 set. 2017.

Altamira. Prefeitura Municipal. Plano Diretor Relatório Final vol. II. Altamira: TECHNUM Consultoria SS., 2010.

Becker, B. K. Geopolítica da Amazônia. Estudos avançados, 19(53), 71-86, 2005. doi: 10.1590/S010340142005000100005

Barbosa, C.; Carvalho, P. F. Zoneamento urbano-ambiental: possibilidades de compatibilização entre análise geomorfológica e padrões de ocupação urbanos para a construção de cidades sustentáveis. In: Cunha, L.; Figueiró, A.; Pedrosa, A. Campar, A.; Rodrigues, L.; Santos, J. G.; Golçalves, A. B.; Vieira, A. B.; Paiva, I. Dimuccio, L.; Mateus, M. (Orgs.). Sustentabilidade da "Gaia": Ambiente, ordenamento e desenvolvimento. Coimbra, Portugal: Editora do Departamento de Geografia/Faculdade de Letras da Universidade de Coimbra, 2010.

Brasil. Relatório de Impacto Ambiental - Rima. Aprovei- tamento Hidrelétrico Belo Monte. Brasília, DF: MME/ Eletrobras/Andrade Gutierrez/Camargo Corrêa, ODEBRECHT, 2009.

Brasil. Presidência da República. Constituição da República Federativa do Brasil de 1988. Brasília, DF: Senado Federal, 1988.

Brasil. Lei ${ }^{\circ}$ 6.938, de 31 de Agosto de 1981. Dispõe sobre a Política Nacional do Meio Ambiente, seus fins e mecanismos de formulação e aplicação, e dá outras providências. Brasília, DF: DOU de 02/09/1981.

Brasil. Portaria $n^{\circ} 47$, de 29 de dezembro de 2006. Dispõe sobre a Avaliação do Potencial Malarígeno e o Atestado de Condição Sanitária para os projetos de assentamento de reforma agrária e para outros empreendimentos, nas regiões endêmicas de malária. Brasília, DF: DOU 04/01/2007.

Brasil. Política Nacional de Atenção Básica. Brasília, DF: Ministério da Saúde, 2012. Disponível em: $<$ http://189.28.128.100/dab/docs/publicacoes/geral/pnab.pdf $>$. Acesso em 14 jun. 2017.

Brasil. Portaria n ${ }^{\circ}$ 2.436/2017, de 21 de setembro de 2017. Aprova a Política Nacional de Atenção Básica, estabelecendo a revisão de diretrizes para a organização da Atenção Básica, no âmbito do Sistema Único de Saúde (SUS). Brasília, DF: DOU 22/09/2017.

Brasil. Avaliação de Impacto à Saúde - AIS: metodologia adaptada para aplicação no Brasil. Brasília, DF: Secretaria de Vigilância Ambiental em Saúde/ Departamento de Vigilância em Saúde Ambiental e Saúde do Trabalhador, 2014.

Cardoso, M. O.; Vieira-da-Silva, L. M. Avaliação da cobertura da atenção básica à saúde em Salvador, Bahia, Brasil (2000 a 2007). Cadernos de Saúde Pública, 28(7), 12731284, 2012. doi: 10.1590/S0102-311X2012000700006

CBERS - Satélite Sino-Brasileiro de Recursos Terrestres. Version 4. Geração de imagens, 2017. Disponível em: $<$ http://www.dgi.inpe.br/siteDgi/portugues/index.php>. Acesso em: 02 out. 2017.

CONAMA - Conselho Nacional do Meio Ambiente. Resolução $n^{\circ} 01$, de 23 de Janeiro de 1986. Dispõe sobre critérios básicos e diretrizes gerais para a avaliação de impacto impacto ambiental. Brasília: DOU de 17/02/1986. 
CONAMA - Conselho Nacional do Meio Ambiente. Resolução $n^{\circ}$ 286/2001, 30 de agosto de 2001. Dispõe sobre o licenciamento ambiental de empreendimentos nas regiões endêmicas de malária. Brasília: DOU 17/12/2001

Conceição, T. S. Trabalhadores nos Canteiros de Obras da UHE Belo Monte-Altamira: condições de saúde e políticas públicas. Belém, Dissertação (Mestrado em Desenvolvimento Sustentável do Trópico Úmido) - UFPA, 2014.

Corrêa, S. R. M. Neodesenvolvimentismo e conflitos sociais: o caso da Hidrelétrica de Belo Monte. Novos Cadernos NAEA, 19(3), 2016. doi: 10.5801/ncn.v19i3.2610

Couto, R. C. S. Saúde e projetos de desenvolvimento na Amazônia: o caso das hidrelétricas. Novos Cadernos NAEA, 2(2), 1999. Disponível em:<http://www.periodicos.ufpa.br/ index.php/ncn/article/view/118/171>

Fernandes, S. C. L.; Vale, M. S. M.; Oliveira, E. A. A. Q.; Dias, N. D. A Evolução espacial da população da microrregião de altamira, no estado do Pará. In: XIII Encontro Latino Americano de Iniciação Cientifica / IX Encontro Latino Americano de Pós Graduação / III Encontro Latino Americano de Iniciação Cientifica Junior, São José dos Campos, 16 e 17 out., 2009. Disponível em: <http://www.inicepg. univap.br/cd/INIC_2009/anais/arquivos/0347_0294_02. pdf $>$. Acesso em 15 jan. 2017.

Fragelli, I. K. Z.; Oliveira, L. S. S. Considerações sobre os impactos em saúde, no contexto do deslocamento forçado de ribeirinhos em Belo Monte. In: Magalhães, S. B.; Cunha, M. C. (Orgs.). A Expulsão de Ribeirinhos em Belo Monte: Relatório da SBPC. São Paulo: Sbpc, 2017. p. 203-234. Disponível em: <http://portal.sbpcnet.org.br/ livro/belomonte.pdf>

Fleury, L. C.; Almeida, J. P. de. A construção da Usina Hidrelétrica de Belo Monte: conflito ambiental e o dilema do desenvolvimento. Ambiente \& sociedade, 16(4), 141158, 2013.

Giongo, C. R.; Mendes, J. M. R.; Santos, F. K. Desenvolvimento, saúde e meio ambiente: contradições na construção de hidrelétricas. Serviço Social \& Sociedade, 123, 501-522, 2015. doi: 10.1590/0101-6628.034

IBAMA - Instituto Brasileiro de Meio Ambiente e dos Recursos Naturais Renováveis. Licenciamento Ambiental
Federal, 2017. Disponível em: <http://www.ibama.gov.br/ legislacao/licenciamento-ambiental> Acesso em: 02 ago. 2017.

IBGE - Instituto Brasileiro de Geografia e Estatística. Estimativa da População 2017, 2017. Disponível em: $<$ http://www.cidades.ibge.gov.br/xtras/perfil.php?lang=\&codmun $=150060 \&$ search $=$ para|altamira $>$. Acesso em: 10 fev.2017.

IBGE - Instituto Brasileiro de Geografia e Estatística. Censos 1920, 1970, 1980, 1991, 2000 e 2010. Disponível em: <http://www.ibge.gov.br>. Acesso em 10 fev. 2017.

IBGE - Instituto Brasileiro de Geografia e Estatística. Cartas e mapas, 2017. Disponível em: $<$ https://downloads. ibge.gov.br/downloads_geociencias.htm>. Acesso em 27 set. 2017

Lessa, A. C. R.; Santos, M. A.; Maddock, J. E. L.; Bezerra, C. S. Emissions of greenhouse gases in terrestrial areas pre-existing to hydroelectric plant reservoirs in the Amazon: The case of Belo Monte hydroelectric plant. Renewable and Sustainable Energy Reviews, 51, 1728-1736, 2015. doi: 10.1016/j.rser.2015.07.067

Magalhães, S. M. S. B.; Hernandez F. M. (Orgs.). Painel de Especialistas: Análise crítica do estudo de impacto ambiental do aproveitamento hidrelétrico de Belo Monte. Belém, 2009. Disponível em: $<$ http://www.xinguvivo.org. br/wpcontent/uploads/2010/10/Belo_Monte_Painel_especialistas_EIA.pdf $>$. Acesso em: 05 fev. 2017.

Malta, D. C.; Santos, M. A. S.; Stopa, S. R.; Vieira, J. E. B.; Reis, A. A. C. A Cobertura da Estratégia de Saúde da Família (ESF) no Brasil, segundo a Pesquisa Nacional de Saúde, 2013. Ciência \& Saúde Coletiva, 21(2), 327-338, 2016. doi: 10.1590/1413-81232015212.23602015

Matos, F. B.; Camacho, J. R.; Rodrigues, R.; Guimarães $\mathrm{Jr}, \mathrm{S}$. C. A research on the use of energy resources in the Amazon. Renewable and Sustainable Energy Reviews, 15(6), 3196-3206, 2011. doi: 10.1016/j.rser.2011.04.012

MS - Ministério da Saúde. E-Gestor Atenção Básica: Informação e Gestão da Atenção Básica, 2018. Disponível em: $<$ https://egestorab.saude.gov.br/paginas/acessoPublico/ relatorios/relHistoricoCoberturaAB.xhtml $>$. Acesso em: 07 ago. 2017. 
Negrão, M. R. G.; Bastos, A. P.; Cardoso, A. C. D. Transformações urbanas na Amazônia: um estudo de caso sobre Altamira. In: Anais da $4{ }^{a}$ Conferência da rede Lusófona de Morfologia Urbana - PNUM, Brasília, 25 e 26 de jun., 4, 1-20, 2015. Disponível em:<http://pnum.fe.up.pt/pt/index. php/download_file/view/251/>. Acesso em 15 jan. 2017.

Neto, J. Q. M. UHE Belo Monte e a reestruturação da cidade de Altamira-PA: agentes, processos e redefinições espaciais. In: XI Encontro Nacional da ANPEGE, Presidente Prudente, 9 a 12 de out., 2502-2513, 2015. Disponível em:<http:// www.enanpege.ggf.br/2015/anais/arquivos/8/242.pdf>. Acesso em 15 jan. 2017.

Neto, J. Q. M.; Herrera, J. A. Altamira-PA: novos papéis de centralidade e reestruturação urbana a partir da instalação da UHE Belo Monte. Confins. Revue franco-brésilienne de géographie/Revista franco-brasilera de geografia, 28, 2016. doi: $10.4000 /$ confins. 11284

Norte Energia. Plano de Requalificação Urbana - Volume III, 2014. Disponível em: <http://www2.defensoria.pa.def. br/portal/anexos/File/BeloMonte/PBA/Volume $\% 20 I I I \% 20$ \%20Tomo\%201-\%20Item\%2005\%20a\%2006/VOL\%20 III\%20-\%20TOMO\%201\%20\%205\%20-\%20plano\%20 requalifica\%20urbana.pdf>. Acesso em: 26 fev. 2017.

OMS - Organização Mundial da Saúde. Constituição da Organização Mundial da Saúde, 1946. Disponível em: $<$ http://www.direitoshumanos.usp.br/index.php/OMS-Organiza $\% \mathrm{C} 3 \% \mathrm{~A} 7 \% \mathrm{C} 3 \% \mathrm{~A} 30-$ Mundial-da-Sa $\% \mathrm{C} 3 \%$ BAde/ constituicao-da-organizacao-mundial-da-saude-omswho. html>. Acesso em: 24 jun. 2018.

Pereira, A. K. Desenvolvimentismo, Conflito e Conciliação de Interesses na Política de Construção de Hidrelétricas na Amazônia Brasileira. Rio de Janeiro: Ipea, 2013. Disponível em: $<$ http://repositorio.ipea.gov.br/bitstream/11058/2001/1/ TD_1884.pdf $>$. Acesso em 12 dez. 2016.

Pontes, A. P. M.; Cesso, R. G. D.; Oliveira, D. C.; Gomes, A. M. T. O princípio de universalidade do acesso aos serviços de saúde: o que pensam os usuários. Escola Anna Nery Revista de Enfermagem, 13(3), 500-7, 2009. doi: 10.1590/ S1414-81452009000300007

Ramos, D. D.; Lima, M. A. D. S. Acesso e acolhimento aos usuários em uma unidade de saúde de Porto Alegre,
Rio Grande do Sul, Brasil. Cadernos de Saúde Pública, 19, 27-34, 2003. doi: 10.1590/S0102-311X2003000100004

Randell, H. The short-term impacts of development-induced displacement on wealth and subjective well-being in the Brazilian Amazon. World Development, 87, 385-400, 2016. doi: 10.1016/j.worlddev.2016.07.005

REN21. Renewables 2017. Global Status Report, 2017. Disponível em: <http:/www.ren21.net/wp-content/uploads/2017/06/17 8399_GSR_2017_Full_Report_0621_Opt. pdf $>$. Acesso em: 05 set. 2017.

Ribeiro, L. C. Q.; Cardoso, A. L. Plano Diretor e gestão democrática da cidade. In: Ribeiro, L. C. Q.; Cardoso, A. L. (Orgs.). Reforma urbana e gestão democrática: promessas e desafios do Estatuto da Cidade. Rio de Janeiro, RJ: Renavam/FASE, 2003. p. 103-118.

Saboya, R. T. (Ed.). Zoneamento e planos diretores. Urbanidades, 2007. Disponível em: <http://urbanidades.arq. br/2007/11/zoneamento-e-planos-diretores $>$. Acesso em: 15 out. 2017.

Sánchez, L. E. Avaliação de impacto ambiental: conceitos e métodos. São Paulo: Oficina de Textos, 2. ed., 2013.

SEPLAN - Secretaria de Planejamento da Prefeitura Municipal de Altamira. Zoneamento de Altamira 2010. Altamira-PA, 2010.

Silveira, M.; Araújo Neto, M. D. Licenciamento ambiental de grandes empreendimentos: conexão possível entre saúde e meio ambiente. Ciência \& Saúde Coletiva, 19(9), 38293838, 2014. doi: 10.1590/1413-81232014199.20062013

Silveira, M.; Padilha, J. B. D.; Schneider, M.; Tavares, A.; Carmo, T. F. M.; Netto, G. F.; Rohlfs, D. B. Perspectiva da avaliação de impacto à saúde nos projetos de desenvolvimento no Brasil: importância estratégica para a sustentabilidade. Caderno de Saúde Coletiva, 20(1), 57-63, 2012. Disponível em:<http://www.cadernos.iesc.ufrj.br/cadernos/ images/csc/2012_1/artigos/CSC_v20n1_57-63.pdf>

Silveira, M. A Implantação de Hidrelétricas na Amazônia Brasileira, Impactos Socioambientais e à Saúde com as Transformações no Território: o caso da UHE de Belo Monte. Brasília, Tese (Doutorado em Geografia) - UNB, 2016.

Teixeira, M. G.; Souza, R. C.; Magrini, A.; Rosa, L. P. 
Análise dos relatórios de impactos ambientais de grandes hidrelétricas no Brasil. In: Müller-Plantenberg, C.; Ab'Saber, A. N. (Orgs.). Previsão de impactos: o estudo de impacto ambiental no leste, oeste e sul. Experiências no Brasil, na Rússia e na Alemanha. 2. ed. São Paulo, SP: Editora da Universidade de São Paulo. p. 162-186, 2006.
Tolmasquim, M. T (Coord.). Energia Renovável: Hidráulica, Biomassa, Eólica, Solar, Oceânica. Rio de Janeiro: EPE, 2016.

Zhouri, A.; Oliveira, R. Desenvolvimento, conflitos sociais e violência no Brasil rural: o caso das usinas hidrelétricas. Ambiente \& sociedade, 10(2), 119-135, 2007. doi: 10.1590/ S1414-753X2007000200008 